\title{
Avaliação e controle da exposição ocupacional à poeira na indústria da construção
}

\author{
Evaluation and control of occupational exposure \\ to dust in the construction industry
}

VIadimir Ferreira de Souza 1

Osvaldo Luís Gonçalves Quelhas 1

${ }^{1}$ Laboratório de Tecnologia, Gestão de Negócios e Meio Ambiente da Universidade Federal Fluminense. Rua Passo da Pátria, 56 São Domingos. 24001-970, Niterói RJ. vladimir@seconcirio.com.br quelhas@latec.uff.br

\begin{abstract}
This work is a intend to evaluate quantitatively the airbornes produced by activities at civil construction on which the construction sites workers are exposed. It identify the necessity of implementing programs to reduce negative impacts in the worker's health. It also intend to classify and identify some of the principal situations and activities of civil construction wherein actually there is most presence of the silica in dust. The study was conducted in several construction sites in Rio de Janeiro. In the field research was determined the respirable dust concentration with dust gravimetric bomb, filtering system (filtres, filtre-holders and holders) and from size particle system (ciclone). The samples analysis was performed in laboratory to determine the quartz by Fourier transformed infrared spectrophotometry (FTIR). This work demonstrates that the development of Environrnental Hazard Prevention Program is part of the most health prevention field and workers integrity, and must being articulated with the Medical ControI Program of Occupacional Health.
\end{abstract}

Key words Construction Industry, Airbornes, Silica
Resumo Este texto trata da avaliação quantitativa dos aerodispersóides gerados por atividades na construção civil aos quais os trabalhadores se expõem. Busca identificar a necessidade de implantar medidas de controle e de redução/eliminação de impactos e incentivar a implantação de programa de proteção da saúde de trabalhadores da indústria da construção. Classifica e identifica as principais situações e atividades geradoras do problema onde há maior presença da sílica livre na poeira 0 estudo foi realizado em canteiros de obra no Rio de Janeiro. Foi determinada a concentração de poeira respirável através de bomba gravimétrica de poeiras, sistema filtrante (filtros, porta-filtros e suportes) e sistema separador de tamanho de partícula (ciclone). A análise de laboratório para determinação da sílica livre foi feita por espectrofotometria de infravermelho por transformada de Fourier. $O$ estudo demonstra que o desenvolvimento do Programa de Prevenção de Riscos Ambientais (PPRA) é parte do conjunto de iniciativas para preservação da saúde e da integridade dos trabalhadores, devendo estar articulado com o Programa de Controle Médico de Saúde Ocupacional (PCMSO).

Palavras-chave Indústria da construção, Aerodispersóides, Sílica 


\section{Introdução}

Os ambientes de trabalho contaminados com poeiras na indústria da construção representam alguns riscos de doenças ocupacionais para os trabalhadores expostos.

Entre essas doenças encontra-se a silicose, principal doença ocupacional pulmonar no Brasil, devido ao elevado número de trabalhadores expostos (René Mendes, 1997). O maior número de casos já encontrados no Brasil é proveniente da mineração subterrânea de ouro em Minas Gerais, onde havia cerca de quatro mil casos diagnosticados até 1992. Logo a seguir vem a indústria cerâmica, fundições, atividades industriais mistas e atividades como a escavação manual de poços e o jateamento de areia. A pneumoconiose dos trabalhadores de minas de carvão vem em seguida, com mais de dois mil casos reconhecidos em benefícios previdenciários. Não há números exatos sobre a doença, nem uma estimativa de população em risco, mas a exposição ocupacional a poeiras com sílica certamente envolve alguns milhões de trabalhadores, nas mais variadas atividades produtivas. Nos países desenvolvidos a silicose é uma doença que se constitui cada vez mais em patologia pulmonar rara em ambulatórios de doenças ocupacionais ou pneumologia.

Alguns motivos que justificam essa situação em nosso meio seriam: o "aquecimento" da atividade econômica e a industrialização relativamente recentes no Brasil; as atividades extrativas e o parque industrial brasileiro que, com exceções, são calcados em tecnologias e equipamentos que não obedecem a padrões de proteção no trabalho e o risco de doenças profissionais começou a ser motivo de pleitos de forma mais rotineira pelos sindicatos dos trabalhadores somente nos últimos anos da década de 1980.

Além disso, a silicose é uma doença causada pela inalação de partículas de dióxido de silício cristalino $\left(\mathrm{SiO}_{2}\right)$, que é um elemento encontrado amplamente depositado nas rochas que constituem a crosta terrestre. Por esse motivo, as atividades industriais que envolvem corte ou polimento de rochas constituem fontes potenciais de sílica respirável. Outras atividades podem também ser incluídas, como a mineração, a abertura de túneis, o trabalho em pedreiras e o corte e a lapidação de pedras. Os usos industriais da areia podem ocasionar exposição a elevadas concentrações de sílica respirável, principalmente o uso da areia com fi- nalidades abrasivas (jateamento de areia). A areia também é amplamente utilizada em trabalhos de fundição, fabricação de vidros e na indústria cerâmica.

Portanto, a silicose pode ser gerada por diversas atividades na indústria da construção. No entanto, seus riscos podem ser reduzidos ou até mesmo eliminados por simples medidas de controle no ambiente e no homem. A principal esperança para a redução da prevalência da silicose repousa na prevenção dos riscos. Os processos industriais que geram sílica livre respirável devem ser compartimentalizados ou modificados; qualquer poeira que contenha sílica jamais deve ser varrida seca, e os trabalhadores devem sempre utilizar equipamento de proteção respiratória individual, a fim de evitar exposições, mesmo por curtos períodos de tempo. Em vários países, por exemplo, não é mais permitido o uso da areia em processos abrasivos, devido à grande quantidade de sílica respirável produzida. Tal proibição deveria ser instituída em todo o mundo, uma vez que existem diversas alternativas disponíveis (granalha de aço e cinza de carvão, por exemplo) (Wyngaarden, 1993).

\section{Desenvolvimento}

\section{Objetivos, delimitação e importância do estudo}

O objetivo deste trabalho é avaliar quantitativamente os aerodispersóides (poeiras) gerados por diversas atividades na construção civil aos quais os trabalhadores em canteiros de obra se expõem, identificando-se a necessidade de implantar medidas de controle e de redução/eliminação de impactos negativos na saúde do trabalhador.

No entanto, um dos principais méritos desta pesquisa é demonstrar que o desenvolvimento do Programa de Prevenção de Riscos Ambientais (PPRA), representando a Higiene Ocupacional, é parte de um conjunto mais amplo das iniciativas da empresa no campo da preservação da saúde e da integridade dos trabalhadores, devendo estar articulado em especial com o Programa de Controle Médico de Saúde Ocupacional (PCMSO).

Este desenvolvimento também pretende classificar e identificar algumas das principais situações e atividades da construção civil e suas fontes geradoras nas quais realmente há maior 
presença da sílica livre na poeira. O estudo foi realizado em vários canteiros de obra localizados no município do Rio de Janeiro, sendo coletadas amostras para avaliação de poeira que poderiam conter sílica livre cristalizada nas atividades mais críticas, como lixamento de concreto de fachada, corte de granitos, escavações manuais, serviços de terraplenagem, preparação de argamassa e corte de elementos estruturais de concreto com o uso de martelete. O trabalho aqui relatado é produto da primeira etapa de um projeto que prevê a aplicação/teste das medidas de gerenciamento sugeridas para redução dos riscos de doenças ocupacionais, especialmente a silicose, nos trabalhadores da indústria da construção.

\section{Metodologia}

\section{População e amostra}

A partir de uma lista das principais atividades na construção civil, que geram poeiras com possíveis percentuais de sílica e após algumas visitas a canteiros de obra, foram definidas as atividades a serem avaliadas.

Em um primeiro momento foram realizadas 14 amostragens de diferentes atividades, tais como:

- terraplenagem

- controle de entrada e saída de materiais do canteiro

- lixamento de concreto de fachada, com utilização de lixadeira elétrica

- escavação e transporte manual de solo

- preparação de argamassa com uso de betoneira sem carregador

- preparação de argamassa com uso de betoneira com carregador

- transporte de saco de cimento

- quebra de elemento estrutural de concreto com uso de martelete

- corte de granito com uso de máquina de corte ("maquita")

- apicoamento de parede de concreto com uso de marreta e ponteira

Após envio das amostras para análise no laboratório, identificou-se com os resultados um percentual de sílica considerável em duas destas situações: lixamento de concreto de fachada e quebra de elemento estrutural de concreto com uso de martelete. A partir daí, para cada uma das situações, foram feitas mais cinco amostras, perfazendo um total de amostras ne- cessário para maior representatividade da presente pesquisa.

\section{Instrumentos de medida}

Os equipamentos de amostragem de poeiras devem simular, da forma mais aproximada possível, o que acontece no trato respiratório, quando da inalação de aerodispersóides. Em outras palavras, o material a ser coletado pelo amostrador somente deverá coletar partículas que tenham a possibilidade de penetrar no trato respiratório (poeira respirável). Dessa forma a amostragem será representativa da exposição ocupacional.

Para avaliação da exposição ocupacional a aerodispersóides foram necessários os seguintes instrumentos:

- bomba gravimétrica de poeira

- sistema filtrante (filtros, porta-filtros e suportes)

- sistema separador de tamanho de aerodispersóide (ciclone)

- termo-higrômetro

- calibrador tipo coluna de vidro

- cronômetro de qualquer natureza com precisão mínima de 1 minuto

\section{Tratamento e análise dos dados}

Os procedimentos e técnicas de amostragem utilizados neste trabalho são baseados nas seguintes normas técnicas:

- NHT 02-A/E - Norma para Avaliação da Exposição Ocupacional a Aerodispersóides;

- NHT 03-A/E - Determinação da Vazão de Amostragem pelo Método da Bolha de Sabão.

Da mesma maneira, a análise gravimétrica de aerodispersóides, ou seja, a determinação da massa de poeira, foi realizada pelo método da Fundacentro (MHA-O2/G - Determinação Gravimétrica de Aerodispersóides) adaptado pelo Centro de Tecnologia Ambiental.

Enquanto que a análise da sílica livre cristalina foi realizada pelo Método NIOSH 7602 espectro fotometria de infravermelho. Com leitura feita a $800 \mathrm{~cm}-\backslash$ resolução de $1 \mathrm{~cm}-\backslash$ com espectrômetro de infravermelho por transformada de Fourier.

\section{Limitações do método}

Por se tratar de um estudo preliminar e de orientação, a estratégia de amostragem adota- 
da foi baseada, apenas, na avaliação das situações e locais considerados críticos em um canteiro de obras. Por isso, não se trabalhou com definição de Grupos Homogêneos de Trabalhadores Expostos ou com Avaliações ao Longo do Tempo, o que tornaria da mesma forma economicamente inviável o presente trabalho. Lembramos que o ideal é realizar amostragens em todos os trabalhadores expostos ao risco, todavia o procedimento pode ser simplificado pelo critério de seleção por grupo homogêneo de exposição. Aliás, mesmo na seleção por grupo homogêneo, que é uma seleção normalizada, na prática encontramos dificuldades em sua aplicação, devido à questão do custo de cada amostragem.

Na grande maioria das empresas do Brasil, dificilmente é realizada mais de uma amostragem em todo grupo homogêneo de exposição, pois a sua direção normalmente considera elevadíssimo o custo de apenas uma amostragem de poeira.

\section{Discussão dos resultados}

\section{Estratégia de amostragem}

As medidas de controle que forem adotadas nos setores considerados mais críticos e nas fontes geradoras de poeira certamente beneficiarão os demais postos de trabalho do canteiro de obras e os demais trabalhadores que exercem suas atividades nas proximidades. As amostras de poeira individuais foram coletadas ao nível respiratório dos trabalhadores, por meio de filtros pré-pesados de PVC, de $37 \mathrm{~mm}$ de diâmetro e porosidade média de $5 \mathrm{~mm}$, utilizando-se de bomba de amostragem individual alimentada por bateria recarregável e com vazão constante dentro de $5 \%$, conforme NHT-O2A1E. A bomba gravimétrica utilizada neste estudo é da marca Mine Safety Appliances Company (MSA), modelo Escort ElfPump.

A vazão de coleta para amostras de poeira respirável (PR) foi de 1,71/min, calibrada segundo a NHT-O3 A1E, com a utilização de um calibrador tipo coluna de vidro disponibilizado pelo Centro de Tecnologia Ambiental.

A poeira respirável foi coletada utilizandose um dispositivo seletor de partículas - ciclone conforme NHT-03A/E. O tempo de coleta variou de acordo com as características do ambiente e das atividades que foram realizadas.

\section{Locais e situações onde foram realizadas as avaliações}

- Lixamento do concreto de fachada: aparelho colocado nos raspadores que operavam as lixadeiras, apoiados em andaimes suspensos mecânicos.

- Abastecimento de betoneira: aparelho colocado nos serventes responsáveis pelos serviços de carregamento do saco de cimento, sua abertura e colocação do cimento na betoneira. Além da exposição ao cimento, tais trabalhadores ficavam expostos a poeira dos outros elementos que compõem uma argamassa, como a areia, saibro e cal.

- Escavação de solo: aparelho colocado nos trabalhadores que cortavam o solo, utilizandose de pás e picaretas, para o acerto e suavização de taludes ao longo das construções. Estes profissionais realizavam o corte do solo (normalmente argiloso e pouco úmido) além do transporte do mesmo por meio de carrinhos de mão. - Arrasamento de estacas moldadas in loco: aparelho colocado em marteleteiros que operavam o martelete para o acerto das estacas de concreto armado envolvidas pelo próprio solo da região.

- Apicoamento de parede: aparelho colocado em pedreiros ao apicoarem as paredes com utilização de marreta e ponteira, envolvendo poeira de cimento e do próprio solo envolvidos na confecção destas paredes.

- Corte de granito: bomba gravimétrica instalada em colocadores de granito nas fachadas, de rodapés e bancadas de pia nas operações de corte do granito com utilização de "maquita".

- Terraplenagem: operação com pá mecânica de carregamento de solo e cal, com o aparelho sendo colocado no operador.

- Vigia: foi instalado o aparelho no vigia que permanecia em local com grande concentração de poeira desprendida pela entrada e saída de veículos carregados de materiais.

\section{Medidas de controle}

Se os resultados obtidos na avaliação dos agentes químicos indicarem valores de concentrações preocupantes quando comparadas com valores cientificamente aceitos, deve ser estudada e implantada uma ou mais medidas de controle para reduzi-los a valores considerados seguros.

Entende-se por controle a eliminação ou a redução dos agentes presentes no ambiente de 
trabalho, até concentrações que não resultem em danos para a saúde da maioria dos trabalhadores expostos, ou ainda a eliminação ou a limitação da exposição a tais agentes (Carvalho, S. A., 1999).

Os sistemas de controle (barreiras de segurança) introduzidos no projeto devem ser previstos para manter os contaminantes em níveis tão reduzidos quanto possível, preferencialmente abaixo do Nível de Ação (50\% do limite de tolerância).

É conveniente analisar a relação custo/beneficio das medidas de controle.

Os sistemas de controle, em geral, estão relacionados a técnicas de engenharia. Dessa forma, cabe destacar que o objetivo principal da engenharia de segurança e higiene ocupacional é: identificar, classificar, mensurar e neutralizar os riscos que resultam da atividade produtiva.

Sendo o perigo definido como a exposição ao risco, cabe lembrar que os métodos de controle são as barreiras de segurança que impedem ou minimizam as exposições.

No controle das doenças ocupacionais provocadas pela inalação de ar contaminado com poeiras, o objetivo principal deve ser minimizar a contaminação do local de trabalho, ou ambiente de trabalho. Isso deve ser alcançado, tanto quanto possível, pelas medidas de controle coletivo, ou seja relativas ao ambiente de trabalho. No entanto, quando essas medidas de controle não são viáveis, ou enquanto estão sendo implementadas ou avaliadas, devem ser utilizadas medidas de controle individual, ou seja relativas ao trabalhador.

Portanto, as medidas de controle da exposição aos aerodispersóides podem ser divididas em duas:

- Medidas relativas ao ambiente de trabalho

- Medidas relativas ao trabalhador

\section{Conclusão}

Observou-se que em quase todas as atividades pesquisadas os trabalhadores não utilizavam equipamentos de proteção respiratória (máscara contra poeiras) ou se beneficiavam de medidas de controle para redução da concentração de poeiras no ambiente. Nas poucas vezes em que algum deles utilizava uma máscara, como no caso do raspador, ou a máscara não era a adequada ou a mesma já não vinha sendo substituída há muito tempo.
Foi constatado que a maioria das empresas dispunha de máscaras contra poeiras, pelo menos as descartáveis, porém alguns trabalhadores não as utilizavam por diversas razões: por falta de uma melhor orientação quanto à importância das mesmas, por não saber que existiam máscaras no canteiro ou por achar que a sua utilização os incomodaria e atrapalharia suas atividades normais.

Com a exceção da aspersão de água sobre o disco da maquita durante o corte de granito, não foi constatada a existência de sistemas de proteção coletiva para prevenir a exposição a poeiras. Na atividade de lixamento de concreto de fachada poderia ser utilizada uma "politriz" já existente no mercado, com sistema de exaustão. Logicamente, antes de seu uso, deve haver uma eficiente análise ergonômica do posto de trabalho de um raspador quando em lixamento de fachada, pois o equipamento poderia se tornar mais pesado e a posição em que o mesmo trabalha não é muito adequada.

É preciso que os próprios equipamentos utilizados pelos trabalhadores amostrados passem por uma manutenção e limpeza periódicas, pois os mesmos encontram-se normalmente impregnados de poeira. Certamente durante a limpeza deve haver também a preocupação com a exposição dos trabalhadores envolvidos na atividade.

Em nenhuma das empresas pesquisadas constatou-se a existência de avaliações e monitoramento quanto às exposições a aerodispersóides ou a implementação eficaz de um Programa de Proteção Respiratória.

A partir de entrevistas diretas com os trabalhadores amostrados percebeu-se que a maioria não realizava há muito tempo ou nunca havia realizado "raios X do tórax".

Com base nos resultados das avaliações e nas visitas feitas aos canteiros de obras pode-se concluir que:

- a exposição dos trabalhadores às poeiras ocorre em vários ambientes de um canteiro de obras, com destaque para as atividades de demolição, perfuração de rochas, terraplenagem, quebra de elemento de concreto com uso de martelete, preparação de argamassa ou concreto em betoneira com carregador e sem carregador, corte de madeiras em serra circular, corte de granito com maquita, lixamento de paredes e tetos com lixa manual, lixamento de concreto de fachada com lixadeira elétrica e limpeza do canteiro com uso de vassoura;

- dentre as situações encontradas em um canteiro de obras, algumas foram avaliadas nesta 
pesquisa. Especificamente nestes casos, as poeiras existentes são, predominantemente, do tipo fibrogênica e contêm sílica livre cristalizada, porém, conforme foi constatado na pesquisa, há também poeiras do tipo incômoda. As atividades cujas amostras coletadas apresentaram sílica foram: lixamento de concreto de fachada, apicoamento de parede de concreto, quebra de contrapiso de concreto com uso de martelete, arrasamento de estaca de concreto com uso de martelete, corte de granito e operações com pá mecânica no transporte de solo e cal.

A partir de um trabalho desenvolvido pela Fundacentro na Bahia para avaliação da exposição ocupacional a poeiras em uma indústria de cimento, constatou-se que as poeiras encontradas foram, predominantemente, as classificadas como incômodas, ou sejam, provenientes de cimento Portland, calcário, argila, gesso e escória. Segundo o mesmo trabalho, na indústria de cimento o teor de sílica livre nas poeiras varia segundo a composição das matérias-primas e da escória ou do cimento, dos quais, normalmente, já se tem eliminado toda a sílica livre.

Nesse mesmo trabalho, constata-se pelos resultados das avaliações das atividades em que a poeira analisada foi a de cimento, que não havia qualquer uma com teor de sílica maior que $1 \%$. Portanto, não podem ser consideradas como poeiras fibrogênicas. Estas foram encontradas somente nas atividades que envolviam o britamento de calcário.

Naquilo que se relaciona às condições especiais de trabalho envolvendo cimento, cal e seus produtos, as prescrições da NR-15, anexo 13, definem que : "As fases de grande exposição a poeiras de cal ou cimento", implicam a obrigatoriedade da existência de grande quantidade de poeira e tempo prolongado de exposição para que as atividades envolvidas com os mesmos possam ser consideradas insalubres. O que segundo os mesmos, são condições que não existem quando da utilização de argamassas prontas e raramente ocorrem quando da confecção de argamassas na obra, já que neste caso a quantidade de cimento movimentado em cada ocasião não se apresenta de modo continuado e por largo tempo. Portanto, as condições a que se refere o anexo 13 são características específicas para fábricas ou distribuidores onde existam quantidades expressivas do material e onde a carga (ou descarga) ocorra de modo continuado.

Ainda com a intenção de comparar o presente trabalho com outras pesquisas dentro desta mesma área de estudo, a partir de um relatório técnico realizado para o SESI do Espírito Santo, no ano de 2000, com o objetivo de analisar a quantidade de sílica livre no ar em obras de construção civil, verificou-se que:

- Em duas avaliações de corte e assentamento de cerâmica em piso de apartamento, todas obtiveram teor de sílica livre maior que $1 \%$. Em uma delas o valor da concentração de poeira respirável coletada foi maior que o LT e a outra teve sua concentração igual ao NA.

- A operação e abastecimento da betoneira utilizando-se cimento, areia e brita foram avaliados através de quatro amostras. Somente em uma delas o teor de sílica livre foi maior que $1 \%$. Porém, a gravimetria coletada foi tão baixa que não atingiu nem mesmo o NA encontrado a partir do teor de sílica livre.

- Foi também avaliado um pintor ao lixar manualmente uma parede de apartamento através de duas amostras. Não se encontrou poeira fibrogênica em nenhuma delas. Porém, verificou-se que uma delas ultrapassou o LT para poeiras incômodas.

Portanto, com base nas avaliações desta pesquisa e nas informações obtidas destes três trabalhos supracitados, concluímos que especial atenção deve ser dada às operações que geram poeiras comprovadamente fibrogênicas e em concentrações capazes de superar o LT definido pela NR-15, anexo 12, para poeiras respiráveis, ou ao menos que superem ao NA, tais como: lixamento de concreto de fachada utilizando-se lixadeira elétrica, demolição de elemento de concreto com uso de martelete, apicoamento de parede de concreto com uso de marreta e ponteira e o corte de granito e cerâmicas.

Devemos destacar que o fato de algumas poeiras analisadas não apresentarem teor de sílica livre suficiente para se caracterizarem como poeiras fibrogênicas não elimina outros potenciais riscos ocupacionais à saúde do trabalhador. Pois, a poeira respirável incômoda pode ser, da mesma forma, causadora de outros tipos de alterações pulmonares que possam determinar o aparecimento de sintomas clínicos, como por exemplo bronquite alérgica. Portanto, especial atenção deve ser dispensada às poeiras com concentrações que ultrapassem o LT para poeiras incômodas.

Certamente, o simples atendimento às recomendações dispostas neste trabalho não implica a eliminação dos riscos da exposição ocupacional a poeiras. O controle efetivo se dá 
através de avaliações periódicas das medidas adotadas, verificando-se permanentemente, a eficiência das mesmas, assim como, os níveis de aerodispersóides no ar.

\section{Referências bibliográficas}

American Conference of Governmental Industrial Hygienist 1999. Threshold limit values for chemical substances and physical, Agents.

Amâncio JB 1993. Pneumoconiose: silicose. In LE Rocha, RM Rigotto \& JTP Buschinelli. Isto é trabalho de gente? Vida, doença e trabalho no Brasil. Vozes, Petrópolis.

Anuário Brasileiro de Proteção, Estatística - Acidentes de Trabalho 2001. Revista Proteção, Novo Hamburgo.

Carvalho AB, Chaves ME Filho, ABX 1993. Relatório da avaliação ambiental de poeiras nas instalações da Cia. de Cimento do São Francisco. CISAFRA, Fundacentro, Centro Regional da Bahia - CRBA.

Carvalho SAM 1999. Apostilas de Higiene industrial agentes químicos. Curso de Engenharia de Segurança do Trabalho da Universidade Federal Fluminense, Rio de Janeiro.

Figueiredo RV 1999. Apostila de Agentes químicos. Curso de Engenharia de Segurança do Trabalho da Universidade Federal Fluminense. Rio de Janeiro.

Fundacentro 1985. Normas de procedimento em higiene do trabalho. NHT-O2A/E. Norma para avaliação da exposição ocupacional a aerodispersóides. Revista Brasileira de Saúde Ocupacional 51(13):63-68.

Fundacentro 1985. Normas de procedimento em higiene do trabalho. NHT -O3A/E. Determinação da vazão de amostragem pelo método da bolha de sabão.

Fundacentro 1985. Programa de Proteção Respiratória: recomendações, seleção e uso de respiradores. Coordenação de Maurício Torloni, São Paulo.

Instituto Nacional de Saúde no Trabalho 1995. Manual de prevenção da silicose. São Paulo.

Kulcsar Neto F 1992. Sílica - manual do trabalhador. Fundacentro, São Paulo.

Leidel NA, Bush KA \& Lynch JA 1977. National Exposure Sampling Strategy Manual. National Institute for Occupational Safety and Health (NIOSH), EUA.

Macedo R 1988. Manual de Higiene do Trabalho na Indústria. Fundação Calouste Gulbenkian, Lisboa.

Marano VP 1977. Medicina do trabalho. Ed. LTR, São Paulo.
Mendes R 1978. Epidemiologia da silicose na região sudeste do Brasil. Tese de doutorado, Faculdade de Saúde Pública da Universidade de São Paulo, São Paulo.

Mendes R et al. 1980. Doenças profissionais causadas por poeiras. In R Mendes. Medicina do trabalho e doenças profissionais. Sarvier, São Paulo.

Mendes R 1997. Patologia do trabalho. Editora Atheneu, Belo Horizonte.

Morrone C 1979. Epidemiologia da silicose no Estado de São Paulo. Dissertação de mestrado, Faculdade de Saúde Pública da Universidade de São Paulo, São Paulo.

MTE 1978. Portaria 3.214/78. Normas Regulamentadoras (NR-7, NR-9 e NR-15 anexos 12 e 13, NR18).

Osha - Occupational Safety and Health Administration 1989. Final Rule Air Contaminants - Permissible Exposure Limits, US. Departments of Labor Occupational Safety and Health Administration.

Philip Drinker SB \& Theodore Hatch BS 1936. Industrial dust hygienic significance, measurement and control. McGraw Hill Book Company, Nova York-Londres.

Rocha LE, Rigotto RM \& Buschinelli JTP 1993. Isto é trabalho de gente? Vida, doença e trabalho no Brasil. Vozes, Petrópolis.

Saliba TM 2000. Manual Prático de Avaliação e Controle de Poeira e Outros Particulados. Editora LTR, São Paulo.

Seaton A 1984. Silicosis. In WKC Morgan \& A Seaton. Occupational Diseases 11:250-294.

Soto JMG 1993. Poeiras e pós. Avaliação ambiental de poeiras. Caderno Técnico da Revista Proteção, Nova Hamburgo.

Wyngaarden JB, Smith LH \& Bennett JC 1993. Tratado de medicina infernal. Editora Guanabara Koogan, Rio de Janeiro.

Artigo apresentado em 20/6/2002

Aprovado em 20/8/2002

Versão final apresentada em 10/8/2003 